\title{
Effects of diode laser irradiation on dental pulps in rats
}

\author{
Guler $\mathrm{C}^{1}$, Alan $\mathrm{H}^{2}$, Demir $\mathrm{P}^{3}$, Vardi $\mathrm{N}^{4}$ \\ Department of Pediatric Dentistry, Faculty of Dentistry, Ordu University, Ordu, Turkey. \\ cigdem_zehir@yahoo.com
}

\begin{abstract}
OBJECTIVES: To evaluate the effects of different power densities of diode laser on dental pulps in rats. BACKGROUND: In this study, we used the maxillary central incisors $(n=80)$ of the 40 adult male Wistar albino rats.

METHODS: Rats were randomly divided into four groups according to power densities of diode laser $(n=10)$. Histopathological changes in pulp and height of odontoblast layer were examined. All data were compared statistically using Mann-Whitney U (Bonferroni) test, $p<0.05$.

RESULTS: G2 displayed slight histolopathologic alterations such as odontoblast cell disorganization and irregularities in cell extensions. Alterations were more prominent in the G3 than G2. Although the lowest odontoblast layer was measured in the G4, the difference in height of odontoblast layer among the groups was not found to be statistically significant.

CONCLUSION: It was concluded that the use of diode laser caused changes at the cellular level in histological examination and may induce the formation of tertiary dentin by influencing the secretory activity of odontoblasts. As long as used in accordance with the recommended procedure, the diode laser can be safely used in dental hard tissues (Tab. 1, Fig. 4, Ref. 15). Text in PDF www.elis.sk.

KEY WORDS: dental pulps, diode laser, male Wistar, cell density.
\end{abstract}

\section{Introduction}

Lasers in dentistry can be used in soft tissue surgery, caries prevention, caries diagnosis, cavity preparation, endodontic treatment, and biostimulation. Different laser are used for biostimulation such as argon, $\mathrm{HeNe}$, gallium-aluminum, $\mathrm{Nd}$ :YAG, and gallium-aluminum-arsenide diode lasers (1).

Low-level laser therapy (LLLT) can be used to ablate enamel and dentin surfaces or to relieve pain and inflammatory tooth pulp conditions (2). However, the effect on dental pulp of laser is still somewhat questionable. Some investigators have shown that functional as well as morphologic changes may occur after irradiating the dental pulp tissue with hard lasers (3-5). However, the biological action of diode laser on the dentin-pulp complex, especially in relation to its different power densities, is not fully understood.

Zach and Cohen (6) reported that a temperature rise of $5.6^{\circ} \mathrm{C}$ in healthy pulp resulted in necrosis in $15 \%$ of the "small teeth" in

${ }^{1}$ Department of Pediatric Dentistry, Faculty of Dentistry, Ordu University, Ordu, Turkey, ${ }^{2}$ Department of Oral and Maxillofacial Surgery, Faculty of Dentistry, Inonu University, Malatya, Turkey, ${ }^{3}$ Department of Pediatric Dentistry, Faculty of Dentistry, Inonu University, Malatya, Turkey, and ${ }^{4}$ Department of Embryology and Histology, Inonu University, Faculty of Medicine, Malatya, Turkey

Address for correspondence: P. Demir, PhD, DDS, Inonu University, Faculty of Dentistry, Department of Paediatric Dentistry, Malatya, 44000 Turkey.

Phone: +90.422 .3410106 .6205 , Fax: +90.422 .3411107$ an animal model. In addition; increase by $10^{\circ} \mathrm{C}$ above the normal body temperature will cause damage to the tissues surrounding the teeth (7). Researchers reported that power output in laser is an important factor affecting tooth pulp chamber temperature (2).

There is only a limited number of studies evaluating the effects of LLLT at different power outputs on the dental pulp $(2,8$, 9 ). Shigetani et al (8) found that diode laser irradiation at higher energy induces apoptosis in the affected dental pulp. In addition they reported that optimal diode laser irradiation elicited intentional tertiary dentin formation in the dental pulp. Tate et al (9) reported that diode laser irradiation induces the formation of tertiary dentin. In addition they found that higher energies cause irreversible changes of the pulp.

The aim of the present study was to investigate the histopathologic changes that occur following different power densities of diode laser on dental pulps in rats. In addition, height of odontoblast layer was evaluated by immunohistochemistry. The null hypothesis tested was that histopathologic changes will occur following different power densities of diode laser on dental pulps in rats.

\section{Materials and methods}

\section{Study design and laser irradiation procedure}

The study was approved by the Inonu University, Experimental Animal Ethic Committee (2012-474). Twenty one adult male Wistar albino rats, initially weighing from $270-300 \mathrm{~g}$ at 3-5 months of age were registered for the study. All the animals were harbored in a room with a cycle of 12 hours of light and 12 hours of dark- 


\section{3-296}

ness. The room temperature was $21^{\circ} \mathrm{C}$ and they were fed ad-libitum. All experimental procedures followed the guidelines for Animal Care and Use Committee of the Inonu Medical University Experimental Animal Center.

The anesthetic was a ketamine hydrochloride $(40 \mathrm{mg} / \mathrm{kg})$ and xylazine $(5 \mathrm{mg} / \mathrm{kg})$ combination administered intramuscularly. Rats were randomly divided into four groups according to power densities of diode laser $(\mathrm{n}=10)$. Two maxillary central incisions in each rat were irradiated with diode laser.

G1: No treatment (control),

G2: irradiated with $15 \mathrm{~J} / \mathrm{cm} 2,0.3 \mathrm{~W}, 30 \mathrm{sec}$

G3: irradiated with $30 \mathrm{~J} / \mathrm{cm} 2,2 \mathrm{~W}, 30 \mathrm{sec}$

G4: irradiated with $60 \mathrm{~J} / \mathrm{cm} 2,4 \mathrm{~W}, 30 \mathrm{sec}$.

The laser tip diameter was $3 \mathrm{~mm}$. The laser tip was kept approximately $1 \mathrm{~mm}$ from (no contact) and perpendicular to the tooth surface. Laser tip was held in the same position so that it did not move across the tooth surface. Laser applications were performed by the same pedodontist (C.G.) to prevent inter-operator variation. Calibration was achieved by a device provided by the laser manufacturer

For easy extraction of the maxillary central incisor teeth, the rats were euthanized by cervical dislocation under inhalation anesthesia $1 \mathrm{wk}$ after the laser irradiations. All maxillary central incisor teeth extraction was performed by the same oral and maxillofacial surgeon (H.A.) to prevent inter-operator variation. Then teeth were submitted to histology.

\section{Histological preparation}

For histological evaluation, teeth were fixed by immersion in $10 \%$ formaldehyde for $72 \mathrm{~h}$. After teeth were treated with $10 \%$ aqueous formic acid solution to remove the calcium from the tissue. Acid solution was replaced with fresh solution every 3 days for 28 days. Subsequently, decalcified teeth were washed in running tap water for 24 $\mathrm{h}$ to remove the decalcifying solutions. Following dehydration in a graded ethanol series, the teeth were embedded in paraffin wax and cut into $6 \mu \mathrm{m}$ sections with microtome (Leica RM 2145). The sections were stained with hematoxylin and eosin. Odontoblast layer was measured using Leica Q Win Image Analysis System (Leica Micros Imaging Solution Ltd, Cambridge, UK) in 10 areas under X40 objective. The sections were examined by a Leica DFC 280 light microscope by a histopathologist (N.V) unaware of the status of animals.
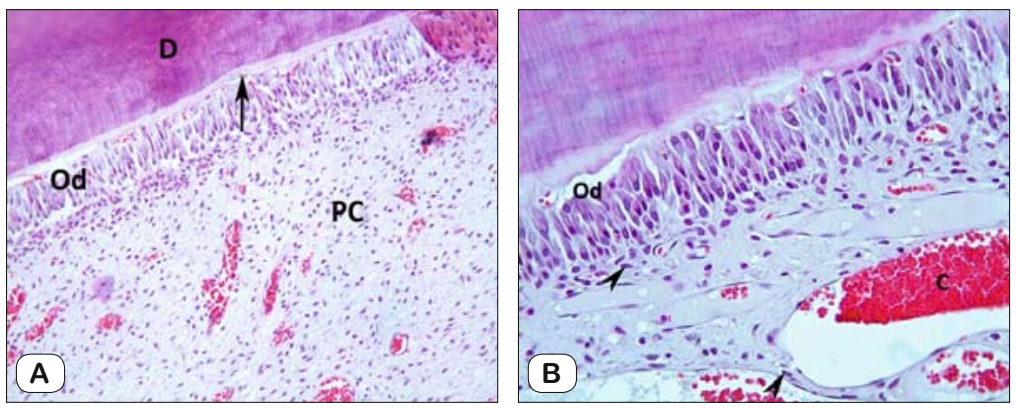

Fig. 1. Control group (G1). A. The appereance of pulpal and dental structure X20, B. Odontoblastic layer $(\mathrm{Od})$ are observed regularly and pseudostratified, arrows indicating fibroblast X40, D: dentine; PC: pulpal core; C: capillaries
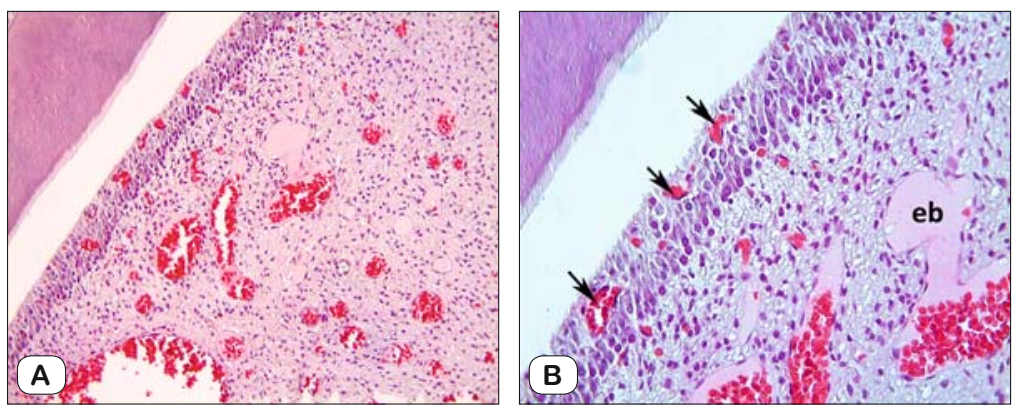

Fig. 2. $15 \mathrm{~J} / \mathrm{cm}^{2}$ group (G1). A. Notice numerous hyperemic capillaries in the pulp X20. B. Capillary vessels are spotted in the odontoblastic layer (arrows) and endothelial budding is seen in the pulpal core (eb) $\mathrm{X} 40$.
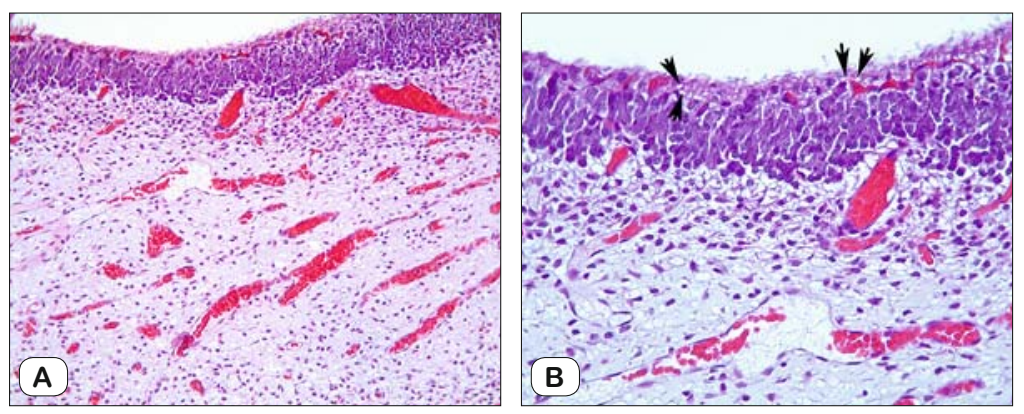

Fig. 3. $30 \mathrm{~J} / \mathrm{cm}^{2}$ group (G3). A. Odontoblast cell disorganization and irregularities in cell extensions are more evident than $15 \mathrm{~J}$ group, X20. B. Arrows showing intracytoplasmic vacuolization in the some of the odontoblast cell processes, $\mathrm{X} 40$.
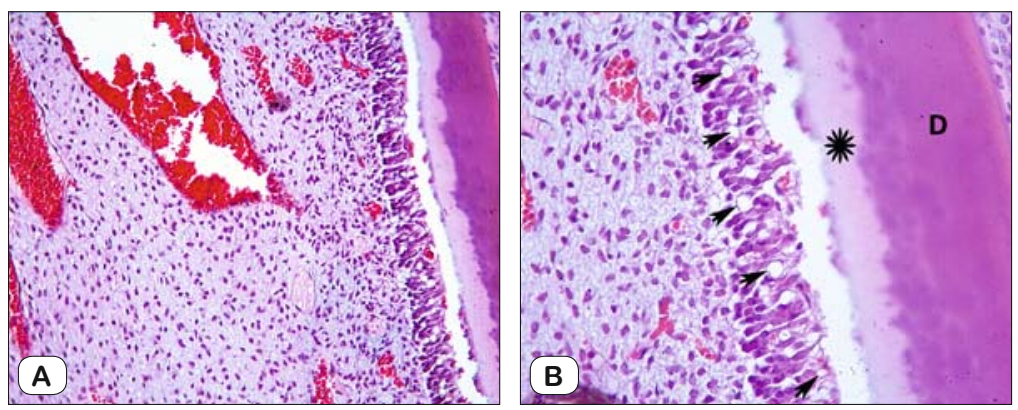

Fig. 4. $60 \mathrm{~J} / \mathrm{cm}^{2}$ group (G4). A. Remarkable increase in cell density in the pulpal core X20. B. Many vacuoles both of cytoplasm and process of odontoblast cells (arrows), X40. Star: predentin, D: dentin. 
Tab. 1. The height of odontoblast layer in all groups ( $\mu \mathrm{m}$; micrometre).

\begin{tabular}{lc}
\hline Groups & The height of odontoblast layer \\
\hline G1 $($ Control $)$ & $120.9(103.0-125.9)$ \\
G2 $\left(15 \mathrm{~J} / \mathrm{cm}^{2}\right)$ & $120.7(108.9-149.7)^{\mathrm{a}, \mathrm{b}}$ \\
$\mathrm{G} 3\left(30 \mathrm{~J} / \mathrm{cm}^{2}\right)$ & $121.6(90.8-137.7)^{\mathrm{a}, \mathrm{b}}$ \\
$\mathrm{G} 4\left(60 \mathrm{~J} / \mathrm{cm}^{2}\right)$ & $108.7(127.5-89.6)^{\mathrm{a}}$
\end{tabular}

${ }^{a}$ Not significant when compared with control group, $p>0.05$

${ }^{\mathrm{b}}$ Not significant when compared with $60 \mathrm{j}$ group, $\mathrm{p}>0.05$

\section{Statistical analysis}

The results of the histologic examination were compared using the SPSS 17 statistical program. Mann-Whitney U (Bonferroni) test was used for comparison between groups. The results are expressed as the median (minimum-maximum). Values of $p<0.05$ were considered significant.

\section{Results}

The pulps of the control teeth (G1) showed normal histological structure. Dental pulp contained fibroblasts, odontoblasts and extensive vascular supply. Odontoblasts exhibited pseudostratified features and extended next to the predentin. Blood capillaries filled with erythrocytes were present in between pulp fibroblasts and in the odontoblast layer (Fig. 1).

The pulps of the $15 \mathrm{~J} / \mathrm{cm}^{2}$ teeth (G2) displayed slight histolopathologic alterations such as odontoblast cell disorganization and irregularities in cell extensions. Further, numerous capillaries were detected in the odontoblast layer and vessels extend into adjacent area by endothelial budding in the pulpal core (Fig. 2).

Odontoblast cell disorganization and irregularities in cell extensions were more prominent in the $30 \mathrm{~J} / \mathrm{cm}^{2}$ group (G3) than $15 \mathrm{~J} / \mathrm{cm}^{2}$ group (G2). Also, vacuoles were observed in some of the of odontoblastic processes in the area close to the dentin. The appearance of pulpal core was similar to $15 \mathrm{~J} / \mathrm{cm}^{2}$ group (Fig. 3).

Marked histological changes in the odontoblast layer were noted such as reduction in cell density of odontoblast and many vacuoles both of cytoplasm and process of odontoblast cells in the $60 \mathrm{~J} / \mathrm{cm}^{2}$ group (G4). Additionally, the increase of pulpal cell density was obvious in the pulp core as compared to the control group (Fig. 4).

Although the lowest odontoblast layer was measured in the $60 \mathrm{~J} / \mathrm{cm}^{2}$ group (G4), the difference in height of odontoblast layer among the groups was not found to be statistically significant.

Inflammatory cellular components such as polymorphonuclear leukocytes were not observed in the pulpal core in any of the groups.

The measure of height of odontoblast layer is shown in Table I.

\section{Discussion}

In modern dentistry, laser irradiation of the tooth surface is a common method which can be used to help vital bleaching, to ablate enamel and dentin surfaces (etching), to relieve pain, depigmentation and inflammatory tooth pulp conditions, the latter being frequently treated with low-level laser irradiation techniques
(10). LLLT are considered as bio modulatory therapies that don't produce important thermal effects on the irradiated tissues. On the other hand, the dental structure has some special characteristics, hydroxyapatite molecules of the enamel and dentin absorb and/or transmit laser energy causing molecular vibration and generating heat that may spread through the pulp tissue (11). In vitro studies have provided contradictory findings of temperature changes in the pulp chamber after low level laser irradiation of the tooth surface $(10,12,13)$. Dangerous temperature rises have been reported in the incisor and canine pulp chambers after a diode laser-activated bleaching $(14,15)$. Even short irradiation periods and low power outputs are likely to raise temperature of pulp to dangerous levels in incisor's thin dentin (13). In addition to dentin thickness it is important to note that the laser parameters used in daily practice should be similar with recommended settings in the World Association for Laser Therapy (WALT) dental treatment guidelines. The reason for the different results reported in the studies may be failing to comply with the described application procedures. Structural changes in the teeth and even complications ranging from the loss of pulp vitality may develop if failure to follow the recommended instructions for each laser type. Therefore, it is important to transcribe irradiation parameters to each laser type and application clinically in order to decrease structural changes to the dental tissues. Each clinician must be aware of the parameters for favorable laser use.

This study was conducted to investigate the potential for pulpal damage using a diode laser and to provide safety conditions for the use of diode laser. The potential for pulpal damage using a power setting of $60 \mathrm{~J}$ is much greater than $15 / 30 \mathrm{~J}$. Odontoblast cell disorganization and irregularities in cell extensions are more evident in the $30 \mathrm{~J}$ than in the $15 \mathrm{~J}$ group. Although the lowest odontoblast layer was measured in the $60 \mathrm{~J} / \mathrm{cm}^{2}$ group (G4), the difference in height of odontoblast layer among the groups was not found to be statistically significant. This study showed that diode laser irradiation at higher energy affected dental pulp such as reduction in cell density odontoblast and many vacuoles both of cytoplasm and process of odontoblast cells. Odontoblasts followed by active cell proliferation may result in abundant tertiary dentin formation. Thus, diode laser irradiation fairly disturbs the odontoblast layer immediately after treatment. LLT does not lead to cause irreversible damage or a loss of vitality in spite of changes at the cellular level in the pulp. Based on these results LLT can safely be used according to the instructions.

With further development of laser devices, researchers focused on developing new laser applications for dental practice, and each year several international meetings are held which bring together this research. These meetings will be considerable opportunity for clinicians to develop and be involved in specific research projects. Considering the future, it is expected that specific laser technologies will become an essential component of modern dental practice over the next decade. As a result of future developments research groups examine uses for lasers in conjunction with or as a replacement for traditional methods.

It was concluded that the use of diode laser causes changes at the cellular level in histological examination and may induce the 


\section{3-296}

formation of tertiary dentin by influencing the secretory activity of odontoblasts. An irreversible change was not observed in this study, however, higher energies may lead to irreversible changes of the pulp, often causes by the formation of an intrapulpal bonelike tissue. As long as used in accordance with the recommended procedure, the diode laser can be safely used in dental hard tissues. LLT systems can be used for management of post-operative inflammation processes and in the enhancement of reparative processes without significant thermal effects, collateral damage to tooth structure, or patient discomfort.

\section{References}

1. Kang KL, Chung JH. Effect of low-energy laser irradiation on healing of extraction sockets in ovariectomized Rats. Tissue Engineering Regenerative Med 2009; 6: 1310-1320.

2. de Alencar Mollo M, Frigo L, Favero GM, Lopes-Martins RA, Brugnera Junior A. In vitro analysis of human tooth pulp chamber temperature after low-intensity laser therapy at different power outputs. Lasers Med Sci 2011; 26 (2): 143-147.

3. Friedman S, Liu M, Izawa T, Moynihan M, Dorscher-Kim J, Kim S. Effects of $\mathrm{CO} 2$ laser irradiation on pulpal blood flow. Proc Finn Dent Soc 1992; Suppl 1: 167-171.

4. Adrian JC. Pulp effects of neodymium laser. A preliminary report. Oral Surg. Oral Med Oral Pathol 1977; 44: 301-305.

5. Melcer J, Chaumette MT, Zeboulon S et al. Preliminary report on the effect of the $\mathrm{CO} 2$ laser beam on the dental pulp of the Macaca mulatta primate and the beagle dog. J Endod 1985; 11: 1-5.

6. Zach L, Cohen G. Pulp response to externally applied heat. Oral Surg. Oral Med Oral Pathol 1965; 19: 515-530.
7. Behnia A, McDonald NJ. In vitro infrared thermographic assessment of root surface temperatures generated by the thermafil plus system. J Endod 2001; 27: 203-205.

8. Shigetani Y, Sasa N, Suzuki H, Okiji T, Ohshima H. GaAlAs laser irradiation induces active tertiary dentin formation after pulpal apoptosis and cell proliferation in rat molars. J Endod 2011; 37 (8): 1086-1091.

9. Tate Y, Yoshiba K, Yoshiba N, Iwaku M, Okiji T, Ohshima H. Odontoblast responses to GaAlAs laser irradiation in rat molars: an experimental study using heat-shock protein-25 immunohistochemistry. Eur J Oral Sci 2006; 114: 50-57.

10. de Alencar Mollo M, Frigo L, Favero GM, Lopes-Martins RA, Brugnera Junior A. In vitro analysis of human tooth pulp chamber temperature after low-intensity laser therapy at different power outputs. Lasers Med Sci 2011; 26 (2): 143-147.

11. McKenzie AL. Physics of thermal processes in laser tissue interaction. Phys Med Biol 1990; 35: 1175-1209.

12. Theodoro L, Haypek P, Bachmann L, Garcia VG, Sampaio JE, Zezell DM, Eduardo Cde P. Effect of Er:YAG and diode laser irradiation on the root surface: morphological and thermal analysis. J Periodont 2003; 74: 838-843.

13. Kreisler M, Al-Haj H, D'Hoedt B. Intrapulpal temperature changes during root surface irradiationwith an 809-nmGaAlAs laser. Oral Surg Oral Med Oral Pathol Oral Radiol Endod 2002; 93: 730-735.

14. Eldeniz AU, Usumez A, Usumez S, Ozturk N. Pulpal temperature rise during light-activated bleaching. J Biomed Mater Res B Appl Biomater 2004; 72: 254-259.

15. Sulieman M, Addy M, Rees JS. Surface and intrapulpal temperature rises during tooth bleaching: an in vitro study. Br Dent J 2005; 199: 37-40.

Received February 26, 2019. Accepted January 8, 20200. 